\title{
EL JUICIO DE GNEO CALPURNIO PISÓN (TÁCITO, ANALES, III 7-18)
}

\section{BARTOLOMÉ SEGURA RAMOS}

Piso, suspected of having murdered Tiberius's adopted son, Germanicus, in October of 19 $\mathrm{AD}$, was brought to trial for this and other crimes in $20 \mathrm{AD}$. The date of the trial (May of the same year) which can be deduced from Tacitus's writings (Annals III 8.15), has traditionally been accepted as accurate. The recent discovery of the SCPP has called this date into question as the Senatus Consultum is dated 10th December, giving rise to the belief that the trial took place round about that time. This study defends the traditional date by combining arguments of historical analysis with an original approach based on breaking down Tacitus's chrono logical-narrative technique into symbolic schemata.

\section{Nuestro tema}

En el año 20, durante el reinado de Tiberio, fue juzgado en Roma bajo la acusación de rebelión armada y sospecha de envenenamiento, Gneo Calpurnio Pisón, que había sido cónsul con Tiberio en el año 7 a. C., y era miembro destacado de la familia Calpurnia, como hijo del célebre Pisón que había luchado contra César, y al que su sucesor, Augusto, hizo todo lo posible por atraerse a su bando, y hombre que, al igual que su padre, poseía un carácter altanero y era violento y rebelde (insita ferocia a patre Pisone: II 43).

Entre el pueblo, empero, más que la rebelión armada, era la extendida creencia de que Pisón había envenenado a Germánico, sobrino e hijo adoptivo de Tiberio, la que lo había puesto en pie de guerra contra él, así como contra el mismo emperador, al que culpaban de haberlo instigado.

Pues en el año 17, tras el triunfo de Germánico, celebrado a finales de mayo en Roma, Tiberio, celoso sin duda de los éxitos de su hijo adoptivo en 
la guerra contra los germanos, había decidido despacharlo a Oriente con el pretexto de organizar la situación allí existente, dotándole del imperium maius, es decir, la facultad "de ejercer un poder superior a quienes por sorteo o enviados por el emperador lo detentasen dondequiera que fuese" (II 43), poniendo al mismo tiempo al frente de la provincia de Siria (la más antigua de Oriente, pues fue creada en el 63 a. C.), precisamente, a este Gneo Pisón, su íntimo amigo, elegido "sin duda - a juicio del propio Pisón -, para poner coto a las esperanzas de Germánico" (ibíd.). Tampoco se dudaba de que Livia, viuda de Augusto, había dado instrucciones a Plancina, esposa de Pisón, para que hostigase a Agripina, esposa de Germánico.

Germánico parte para Oriente a finales del año 17, y el 1 de enero del 18, año para el que había sido nombrado cónsul, le sorprende en Nicópolis (Acaya), donde se ha detenido algún tiempo para reparar las naves. A partir de ese punto emprende un largo itinerario, fundamentalmente turístico, durante el cual, aparte de visitar múltiples lugares, se produce el nacimiento de su última hija, Julia Livila, en la isla de Lesbos (¿mes de febrero?). En junio, probablemente, arriba por fin a su destino, y parte para Armenia. Pasa el verano en esta provincia (en realidad, estado colchón entre Partia y Roma, potencias bajo una de las cuales se halló alternativamente siempre y contra las cuales hubo de combatir sin tregua, así como en Commagene y Capadocia). Entretanto, Pisón se ha ido ganando a las legiones de Siria (en especial, la VI Ferrata) y cuando Germánico le pide que conduzca parte del ejército a Armenia, él mismo o por medio de su hijo Marco, hace caso omiso de ambas cosas (II 57). Por último, los dos se ven las caras en Cirro, ciudad al norte de Siria, en los cuarteles de invierno de la legión X, probablemente hacia el mes de octubre, una entrevista en la que quedó clara la incompatibilidad entre ellos, y de la que se despidieron con odio mutuo. Al año siguiente, el 19, Germánico marcha a Egipto, otra vez a hacer turismo. A su regreso (¿a principios de julio?), halla que han sido revocadas sus órdenes y abolidas sus disposiciones. Se produce un cruce de duros reproches entre Germánico y Pisón, que decide abandonar Siria.

Poco después, el joven príncipe cae enfermo (¿mes de agosto? Suetonio habla de una larga enfermedad - Calígula 1,1: diuturno morbo -. Germánico morirá el 10 de octubre), y durante ese tiempo Pisón aguarda el desenlace de la enfermedad en la ciudad siria de Seleucía. Entonces, Germánico, asus- 
tado y temeroso de haber sido envenenado, retira su amistad a Pisón mediante una carta (II 70) y le ordena que abandone Siria. Sin más demora, Pisón embarca y se aleja, y hallándose en la isla de Cos, al sur de Caria (¿a tres o cuatro días de Seleucía en Siria?), recibe la noticia de la muerte de Germánico, acontecimiento que le llena de alegría y que lleva a Plancina a quitarse el luto por la muerte de una hermana (II 75).

Los generales deliberan para ver quién se encarga del gobierno de Siria, y a la postre éste es confiado a Gneo Sencio, quien de inmediato ordena a Martina, una conocida envenenadora, partir para Roma, ya desde ese instante acusada por los amigos de G., Vitelio y Veranio. Agripina, por su parte, deseosa de hacer justicia, embarca con las cenizas de su esposo ( $i 25$ de octubre?), y al costear Licia y Panfilia se cruza con la nave de Pisón, quien ha dado vuelta y regresa con la intención de recuperar su poder en Siria: Vibio Marso, acompañante de Agripina, le comunica que debe acudir a juicio a Roma (II 79). Mientras aquélla prosigue su marcha hacia Roma, el aristócrata organiza un pequeño ejército, en la creencia de que las legiones, a las que ha obligado a llamarle padre de las mismas, le van a apoyar, y toma el pequeño sitio de Celénderis, en Cilicia, adonde acude presuroso Sencio, que le derrota. Pisón se da entonces por vencido, y pide permanecer en el castillo de la ciudad hasta que se consulte a Tiberio quién debe mandar en la provincia. No aceptó Sencio semejantes condiciones, y sólo transigió con poner un barco a su servicio y darle vía libre para Roma (II 81: ¿25 de noviembre?).

Mientras, en Roma se recibe la noticia de la muerte de Germánico; después, se desmiente, y por fin se confirma definitivamente (II 82). El senado decreta el iustitium el día 8 de diciembre (EJ, p. 41), y el 16 del mismo mes (a saber, un nundinum más tarde, a. d. XVII Kal. Ian. - cf. González, J., Estudios sobre la Tabula Siarensis, Madrid, 1988, pp. 307-315, IIb 12) se aprueba un senadoconsulto acerca de los honores oficiales al príncipe fallecido (II 83). Sus cenizas llegan a Roma probablemente el 8 de enero del año 20 (III 2 consules - iam enim magistratum occeperant - et senatus ... uiam compleuere).

¿Cuándo tuvo lugar el juicio de Pisón, con cuyo suicidio quedó saciada en parte, al menos, el ansia de venganza del pueblo romano y de los amigos del joven príncipe? Según se desprende del relato de Tácito (y así se ha 
aceptado unánimente desde siempre), dicho juicio tuvo lugar en la primavera del año siguiente a su muerte, año 20. Conforme con el SCPP, recientemente descubierto (cf. Caballos, A., Eck, W., Fernández, F., pp. 143-148; Woodman, A.J., pp. 69-75), el juicio habría concluido el 10 de diciembre (SCPP: a. d. IIII Eid. Dec. -línea 1 -; IIII Idus Decem. - línea 175), y por tanto se habría celebrado entre finales de noviembre y la fecha en cuestión.

Una fecha ajena a la narración de Tácito, pues (la del SCPP), ha suscitado la tesis de la datación a final de año del juicio contra Pisón, y una fecha igualmente ajena a la narración de Tácito (la de la ouatio de Druso, hijo de Tiberio, datada el 28 de mayo del mismo año, el 20, por los Fastos Ostienses) alimenta la fe en la datación taciteana del juicio de Pisón en el mes de mayo, como tradicionalmente se ha venido aceptando sin discusión. ¿Cuál de las dos fechas ajenas a la narración de Tácito ha de tener más fuerza, por consiguiente? ¿Cuál de las dos ha de ser más probatoria y capaz de inclinar la balanza a su favor?

Insistamos ante todo en el hecho innegable de que hasta el descubrimiento del SCPP nadie en el mundo de la Filología ni de la Historia había puesto pega alguna a la narración de Tácito, que claramente sugiere la primavera del año 20 como época de la celebración del juicio a Pisón. Y convengamos, por otro lado, que la duda o el rechazo olímpico de dicha narración se ha planteado exclusivamente con el descubrimiento del famoso senadoconsulto, cuya fecha de emisión, dada, como hemos visto arriba, tanto en la praescriptio como en la subscriptio, no deja lugar a dudas: 10 de diciembre. A partir de ese momento es cuando se han buscado y hallado pegas de todo tipo al relato taciteano:

a) Necesidad de un amplio período de tiempo para el enfrentamiento de Pisón con las legiones al mando de Gneo Sencio (II 80-81).

b) Necesidad igualmente de más tiempo para el viaje de Druso al Ilírico, así como su vuelta (III 7).

c) Necesidad de un amplio intervalo de tiempo para el nombramiento de defensores de Pisón, envío de la causa a Tiberio y devolución de la misma al senado (III 10-11); etc., etc.

En una palabra, el período de tiempo comprendido entre la muerte de Germánico (10/10/19) y la fecha presumible del juicio (mediados de mayo 
del año 20), en total, siete meses, parece ahora demasiado corta para que se desarrollen tantos acontecimientos:

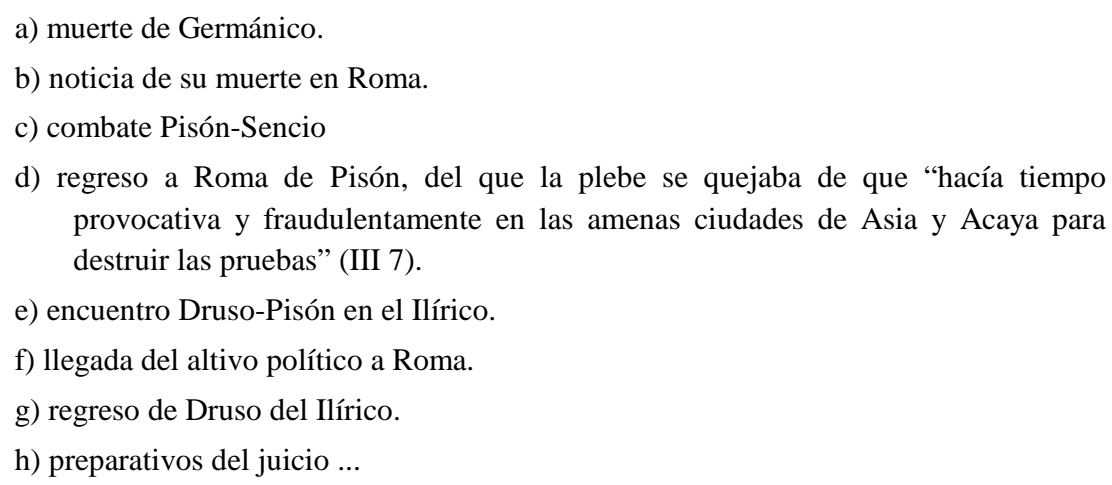
provocativa y fraudulentamente en las amenas ciudades de Asia y Acaya para destruir las pruebas" (III 7).

e) encuentro Druso-Pisón en el Ilírico.

f) llegada del altivo político a Roma.

g) regreso de Druso del Ilírico.

h) preparativos del juicio ...

Por tanto, en el presente escrito procede demostrar estos dos supuestos:

1. Que los siete meses transcurridos entre la muerte de Germánico y el juicio de Pisón, hipotéticamente en el mes de mayo, es un lapso de tiempo suficiente para que el juicio tenga lugar, y que, por tanto, no hay ninguna necesidad de retrasarlo seis meses y medio (hasta primeros de diciembre).

2. Que el modo en que Tácito narra el juicio y sus antecedentes se adecua perfectamente al método por él seguido en los 43 libros de los Anales (de los que en parte o en su totalidad nos ha llegado la versión del historiador romano), y que de esta manera las claras sugerencias cronológicas que apuntan a la celebración de dicho juicio en el mes de mayo se desprenden de su relato en la misma forma como se desprende en el resto de su narrativa histórica, por lo que podemos manifestar que en esta parte de nuestra demostración no pretendemos tanto dar fe de la veracidad histórica del autor latino y defender, por así decir, a capa y espada la versión que presenta de los hechos, particularmente en su aspecto cronológico, cuanto corroborar, $1^{\circ}$ ) que Tácito sigue un método narrativo-histórico en toda su obra, al cual se atiene rigurosamente, y $2^{\circ}$ ) que conforme a dicho método, los hechos que confluyen en el asunto que estamos debatiendo en esta ocasión se producen temporalmente (esto es, en el tiempo) de la manera que su narración sugiere. ${ }^{1}$

1 Por lo que atañe al $S C P P P$ en sí, debemos decir que, en puridad, éste nada tiene que 


\section{El tiempo transcurrido entre la muerte de Germánico y la celebración del juicio}

\section{El reo: Gneo Calpurnio Pisón}

¿Pudo el reo, Gneo Pisón, regresar a Roma a tiempo de ser juzgado durante el mes de mayo? Evidentemente, sí, pese al mal tiempo para navegar, y no hay mejor prueba que el viaje de Agripina, quien, proveniente del mismo lugar, estaba en Roma a principios de enero del año 20 (III 1-2).

Sólo que Agripina anhelaba llegar a Roma para hacer justicia (II 75: omnium ... quae ultionem morarentur intolerans), en tanto que para Pisón hay que contar con dos inconvenientes: $1^{\circ}$ ) su pretensión de recuperar el poder de la provincia (Siria), que le lleva a una aventura bélica (II 76-81), y $2^{\circ}$ ) sus escasas prisas por comparecer ante la justicia (III 7: quod uagus ... per amoena Asiae atque Achaiae).

Tratemos primero el primer punto. Habíamos dejado a Pisón y a Plancina en el instante en que, tras enterarse de la muerte de Germánico durante su estancia en la isla de Cos (II 75), y regocijarse y expresar públicamente ambos su alegría por dicha muerte, sus barcos se cruzaban con los de Agripina en la costa de Licia y Panfilia (II 79). Debía ser probablemente el 28/29 de octubre (v. infra). En ese momento, una vez muerto Germánico, Pisón aspiraba a hacerse de nuevo con Siria, desoyendo los consejos de su

ver con la narración de Tácito y la secuencia cronológica que de ella se desprende (en tanto, por el contrario, sí tiene que ver, y mucho, la celebración de la ouatio de Druso el 28 de mayo), y en todo caso dicho senadoconsulto requeriría una explicación por sí mismo, ya que su emisión en la fecha por él declarada no contradice la celebración del juicio seis meses y medio antes (pues tampoco afirma que el juicio se haya celebrado en el mes de diciembre), pudiendo y debiendo justificarse la publicación de semejante senadoconsulto en la fecha mencionada, pese a la distancia temporal con la finalización del proceso, a cuyo fin algunos indicios tal vez quepa rastrear en la redacción misma del documento senatorial. — En realidad, es a quienes defienden la fecha del senadoconsulto como fecha del juicio a quienes corresponde la obligación de demostrar que esa es la fecha del juicio contra Pisón. Pues a nosotros sólo nos compete decir que un senadoconsulto de esa naturaleza no tiene por qué ver con la celebración del juicio al que alude: también Nerón, a raíz del incendio de Roma en el año 64 (XV 38-45) tiene que salir al paso de los rumores que apuntaban hacia él como culpable del incendio: ergo abolendo rumori Nero subdidit reos et quaesitissimis poenis adfecit quos per flagitia inuisos uulgus Christianos appellabat (ibíd., 44), una medida que no debió tomarse antes de octubre, por lo menos, esto es, tres meses después del incendio de Roma, ocurrido el 19 de julio. 
hijo Marco (II 76) y cediendo a los requerimientos de Domicio Céler (ib. 77). En los días previos a esa fecha (digamos, a partir del día 14; v. infra), Pisón había tenido tiempo para: a) felicitarse por la muerte de Germánico; $b$ ) celebrar consejo con su hijo y Domicio Céler; $c$ ) enviar a éste a Siria por alta mar (ib.78), y d) organizar a los desertores, armar a los buhoneros, secuestrar una bandera de reclutas que marchaban a Siria y escribir a los régulos cilicios pidiéndoles colaboración. Todo ello es posible en un par de semanas, porque $a$ ) puede durar unos días sin excluir $b$ ) y $c$ ), que pueden a su vez ser liquidados a la semana, en tanto que $d$ ) puede, solapándose parcialmente, con $a$ ), $b$ ) y $c$ ), solucionarse en 10 días: los desertores acudían a él (II 76), los buhoneros estaban a su lado, y la bandera pudo ser fácilmente interceptada en un audaz golpe de mano. Por lo demás, su hijo Marco debía llevar el peso de la acción (haud ignauo ad ministeria belli iuuene Pisone: II 78). En todo caso, tales movimientos son anteriores al encuentro con Agripina (II 79), y que ésta se hallase en tal fecha (28/29 de octubre) en el lugar indicado (a dos o tres días de Antioquía) es más que probable, si tomamos en consideración el hecho irrefutable de que hacia el 18 ó 20 de diciembre (54 días más tarde) la flota de la princesa atraca en Brindis (v. infra), si es que queremos que, como se colige claramente de III 2, los restos mortales de G. lleguen, siguiendo la vía Apia, finalmente a Roma hacia el 8 de enero.

Tras dicho encuentro, que, no lo olvidemos, debió producirse hacia el 28 ó 29 de octubre, se suceden los siguientes hechos:

1. Sencio escribe a Pisón para que no persista en amotinar las tropas, dado que Domicio ha llegado a Laodicea, al sur de Antioquía hacia el 29 de octubre (interim: II 79), con la intención de sublevar a la legión VI Ferrata, cosa que frustra su comandante, Pacuvio (ibíd.), al tiempo que se prepara para cualquier contingencia;

2. Pisón, que ya no volverá a Siria jamás, decide entonces tomar al asalto el castillo de Cilicia, cercano al mar, llamado Celénderis, empleando para ello una especie de legión que ha organizado con los siguientes elementos: a) conocidos (supra, 78), a saber, desertores y reclutas; b) nuevos (ib., 80), a saber, mercenarios ya enviados por los régulos, más la servidumbre propia y la de Plancina;

3. choque con las legiones de Sencio delante de las murallas, y desbandada general de cilicios y buhoneros;

4. intento fracasado de sublevación de la escuadra por parte de Pisón;

5. asalto del castillo por las legiones comandadas por Sencio y rendición sin condiciones de Pisón (81). 
¿Cuánto tiempo pueden llevar estos hechos?

1. Sencio separa a los partidarios de G. de los posibles revoltosos y forma con ellos una tropa valerosa, dispuesta a combatir (79): esto es cuestión de unos pocos días (¿7/8? Pues, evidentemente, las circunstancias urgen);

2. Pisón conquista Celénderis nada más tener noticias de que Domicio no ha logrado nada y recibir la carta de Sencio (80: arceri a Sentio priuatum odium falsis criminibus tegente (la conquista en sí puede llevarse a cabo en un día; Pisón ha tenido que desembarcar - ¿el 31 de octubre? -, organizar la legión - ¿5 ó 6 días?: 6/11-);

3. Sencio, viniendo de Seleucía con sus legiones, ha podido plantarse en la cercana Celénderis, en pocas jornadas (¿6 ó 7 días más tarde de separar a los partidarios de G., dado que 6 días son suficientes para que una legión se ponga en camino? Luego 7/8 más $6 / 7=15$ días, contados a partir del 29 de octubre, $=13$ de noviembre);

4. El intento personal de Pisón de sublevar la escuadra (81) puede llevar días u horas. En cualquier caso, dicho intento se produce simultáneamente a la desbandada de los cilicios (interim: 81). Digamos que a mediados de noviembre;

5. A la desesperada, Pisón hace un último intento de sublevar a los legionarios, y un abanderado de la VI Ferrata deserta a él. En ese momento (tum: 81), Sencio ordena el asalto. Tandem uicta pertinacia, Pisón se rinde. ¿En cuántos días pueden suceder estos acontecimientos? ¿Tres? ¿Cinco? ¿Diez? Nos hallaríamos, pues, finalmente, hacia el 25 de noviembre.

En resumidas cuentas: los acontecimientos que tienen lugar desde el encuentro con Agripina en el mar hasta la rendición de Pisón en Celénderis (Cilicia) apenas pueden durar un mes. Pues Domicio llega a Laodicea en cuestión de unos días; Sencio reacciona y organiza el ejército en cuestión de días también, avanza hacia Cilicia, adonde Pisón ha llegado fácilmente (porque se halla muy cerca y ya ha avisado previamente a los régulos por escrito); el choque no dura ni un día ( ut uenere in manus non ultra dubitatum: 80). De modo que el tiempo que le hemos asignado a este período (un mes) incluso puede resultar excesivo. Por lo demás, una vez vencido Pisón, se le facilitan naves y un viaje con garantías a Roma (tutum in urbem iter concessum est: 81). Cuando volvemos a oír de él es en III 7 (año 20), en que llega al Ilírico para entrevistarse con Druso, presumiblemente, el 8 ó 10 de abril. Para entonces han transcurrido cuatro meses y medio.

¿Qué ha hecho Pisón durante ese tiempo? Naturalmente, sólo sabemos lo que Tácito dice o insinúa, y el historiador afirma en primer término que Gneo Sencio, el gobernador de Siria, le concede, al vencerle, un salvoconducto para Roma. Desde ese momento, como hemos visto, el republicano rebelde dispone de más de cuatro meses hasta su encuentro con Druso. La 
gente en Roma se queja de que se retrase en comparecer ante la justicia (III 7): según se dice ahí, Pisón remoloneaba por Asia y Acaya (Grecia) deteniéndose en lugares de recreo (amoena). Ahora bien, en el mismo pasaje se afirma que su objetivo no era tanto el turismo como destruir pruebas (y por lo que se nos dice a continuación se trataba de una sola prueba: el asesinato de Martina, la envenenadora). Pero Martina había sido enviada a Roma por Gneo Sencio, postulantibus Vitellio ac Veranio (II 74), y ello había sido a raíz de la muerte de Germánico. Por tanto, su envío debió tener lugar muy pronto (¿15 de octubre?). De esta forma, la muerte de Martina (quien, como vemos, ha partido de Siria antes que Agripina), que tiene lugar en Brindis, pudo haber ocurrido perfectamente a primeros de diciembre, fecha en que Pisón ya había recibido orden de partir a su vez hacia Roma y en la cual fecha, liberado de su aventura en Cilicia, disponía de tiempo para ordenar la eliminación de la envenenadora. De modo que durante ese mes de diciembre es cuando Pisón se halla en Asia.

Nos hallamos en invierno, y en esa época no se suele navegar por los peligros que entraña la navegación. Ahora bien, aparte de que en ese momento justo Agripina navega hacia Italia, ¿cuánto tiene que navegar Pisón? Supongamos que se pasa en Asia el mes de diciembre. El 1 de enero decide pasar a Acaya: sólo tiene que atravesar el mar Egeo para de isla en isla (como solía navegarse) llegar en muy poco tiempo a Eubea. Y ya está de nuevo en tierra firme. Todavía dispone de los meses de enero y febrero para andar uagus por Acaya (Agripina ya ha llegado a Roma): ese es el momento del crebro questu de la plebe (III 7). Por último, en marzo decide acercarse a su predio (regalo de Augusto) del Ilírico (SCPP 84-85: utique bona Cn. Pisonis patris publicarentur excepto saltu, qui esset in Hillyrico) y, sabedor de que Druso vendría a la provincia, resuelve visitarlo para ganárselo en la inevitable e inminente causa que le aguardaba en Roma (8/10 de abril). Acto seguido, atraviesa el Adriático, en Ancona toma la vía Flaminia, y en menos de quince días arriba a Roma (25/4). El 26 de abril se le declara imputado.

\section{La acusación: Vibio Marso, Vitelio, Veranio, etc.}

En su lecho de muerte, Germánico pide a sus amigos que le venguen, que hagan justicia: erit uobis locus querendi apud senatum, inuocandi leges (...) amicorum munus est (...) quae uoluerit meminisse, quae mandauerit exequi (...) uindicabite uos (...) misericordia cum accusantibus erit (II 71). Y sus 
amigos aceptaron inmediatamente el reto: iurauere amici...spiritum ante quam ultionem amissuros (ib.). Como esta conversación tuvo lugar, según el historiador, ubi finis aderat (ib.), y dado que posiblemente los últimos días no pudo hablar (II 72), podemos suponer que ocurrió efectivamente hacia el 6 ó 7 de octubre. Luego, el 15 del mismo mes, Gneo Sencio, como hemos visto, "envió a Roma a Martina", postulantibus Vitellio ac Veranio ceterisque qui crimina et accusationem tamquam aduersos receptos iam reos instruebant (II 74), donde, dicho sea de paso, se habla en plural (reos), lo cual sólo puede implicar que, además de Martina, se alude a Pisón y Plancina.

Por su parte, Agripina parte de Antioquía el 25 de octubre, omnium quae ultionem morarentur intolerans (II 75), lo que quiede decir que su rápida marcha tiene como objeto pedir a Tiberio que castigue a Pisón. ¿Qué imaginaremos que va a hacer o decir Agripina desde el instante mismo de su llegada a Roma el 8 de enero? ¿Y sus impacientes amigos? Hacia el 20 de octubre, o poco antes, Domicio Céler acaba por convencer a Pisón de que debe hacer valer sus derechos sobre Siria con los siguientes argumentos: “Nos daremos prisa para atracar junto a las cenizas de Germánico (pues su hijo, Marco, le había aconsejado partir inmediatamente para Roma - properandum in urbem: 76,1$)$ y para que el duelo de Agripina y el vulgo ignorante te arrebaten al primer rumor, sin oírte ni defenderte?" (II 77).

Por último, el 28 de octubre, según se ha visto, Pisón y Agripina se cruzan en el mar, y Vibio Marso, que acompaña a Agripina en su viaje a Roma, nuntiauit Pisoni Romam ad dicendam causam ueniret; ille eludens respondit adfuturum ubi praetor (el presidente del tribunal) qui de ueneficiis quaereret (SCPP 121-122: aqua et igne interdici oporteret / ab eo praetore qui lege maiestatis quaereret) reo (Pisón) atque accusatoribus (Vibio, Vitelio y los demás) diem prodixisset (II 79).

Por consiguiente, tenemos cinco referencias claras al juicio contra Pisón en la narrativa anterior al año del proceso, el 20, todas ellas en octubre del 19, el mes de la muerte del príncipe romano, y atribuidas a ambas partes: de un lado, la víctima, Agripina y los acusadores, y del otro, el reo y su amigo Domicio. La víctima pide venganza antes de morir; su esposa se muere de impaciencia por vengarse, sus amigos claman justicia y parten para Roma a exigirla de inmediato, Céler, el amigo de Pisón, invita a éste a dar largas al asunto, el reo, aunque mofándose, admite que cuando haya citación judicial tendrá que acudir al juicio. 
Por otra parte, llegados Agripina y los acusadores a Roma, lo más tarde el 8 de enero ${ }^{2}$, ¿qué otra cosa van a hacer sino pedir, exigir a Tiberio el encausamiento de Pisón? Éste se halla a la sazón (v. supra I 1) en Acaya. Nada más natural que el hecho de que el entierro de Germánico (tal vez el 15 de enero, un nundinum después de la llegada a Roma) se envíe a Pisón la orden de regresar a Roma. Dicha orden puede ser cursada por Tiberio a finales de enero, y llegar a manos de Pisón a lo largo del mes de febrero. El reo dispone a partir de ese instante de tiempo más que suficiente para volver a Roma y llegar a tiempo de ser juzgado desde finales de abril en adelante.

\section{Druso y su relación con el proceso}

Druso, el hijo de Tiberio, aparece mencionado en tres ocasiones en estrecha relación con el juicio de Pisón:

$1^{a}$. Por su encuentro con Pisón en el Ilírico (encuentro no mencionado en las demás fuentes; III 8);

$2^{\text {a }}$. Por su regreso a Roma durante la fase de instrucción del proceso, ocasión en que aplaza la celebración de la ouatio (III 11).

$3^{\text {a }}$. Tras la finalización de aquél, momento en que sale de la ciudad a retomar los auspicios, vuelve a entrar y celebra finalmente la ouatio (III 19).

Cabe preguntarse qué interés tenía Tácito en vincular tan íntimamente a Druso con el juicio de Pisón. Pues se podría alegar que el encuentro en el Ilírico era un deber histórico contarlo, aun cuando, como hemos reseñado, semejante encuentro es silenciado por las restantes fuentes. Pero las otras dos citas, vuelta a la ciudad durante el proceso y alusión a su ouatio como broche absoluto del mismo, no se ve qué obligación tenía el autor de hacerlas. En general, el historiador pudo obviar las tres referencias sólo con suprimir la frase et Drusus Illyricos ad exercitus profectus est, así como el capítulo 8, y naturalmente evitando las otras dos menciones, que no se ve qué relación

2 Cuando los cónsules, el senado y gran parte del pueblo salen a recibir las cenizas de Germánico, lo hacen a la Vía Apia (uiam oppleuere: III 2), pero en la vecindad de Roma, ya que de Druso se dice que salió hasta Terracina (a 103 kms. de Roma, "un solo día de camino": III 5), dándose a entender así que la cercanía de Roma en el caso de los demás queda fuera de toda duda. En ese momento, el historiador afirma, tras nombrar a los cónsules, que "ya habían iniciado sus funciones", lo que implica, dado que Agripina y sus acompañantes han llegado a Brindis todavía en diciembre, que "acaban de tomar posesión", y por tanto la fecha propuesta no debe andar lejos de la realidad. 
pueden guardar con el proceso. Hecho esto, es decir, rota la conexión del juicio con Druso, dicho juicio quedaba temporalmente libre, en el aire, sin anclaje a lo largo del año, y de este modo lo mismo daba asignarlo a la primavera, que al verano o al invierno. Y esta es la razón por la que debemos preguntarnos el motivo que llevó a Tácito a establecer dicha conexión, estructuralmente, innecesaria, entre el hijo del emperador y el juicio. Y la respuesta no puede ser otra que la siguiente: porque Druso tenía vivo interés en vengar la muerte de Germánico, su hermano adoptivo, con el que siempre se llevó a las mil maravillas (cf. II 43 - año 17: sed fratres egregie concordes et proximorum certaminibus inconcussi). Y aparte de mostrarse unidos frente al senado en el caso del pretor que había de sustituit a Vipstano Agripa (II 51, mismo año), cuando Germánico iba camino de Oriente a finales de ese año 17, uenerat per Illyricam oram uiso fratre Druso in Delmatia agente (II 53 - año 18).

Así que mientras Tiberio, Augusta y por supuesto los amigos de Pisón hubieran deseado echar tierra al asunto, a tenor de las dudas que acerca del papel desempeñado por los primeros en el acoso de G.existían, Druso era tal vez el único miembro de la familia imperial que tomaba parte por Germánico, junto a la plebe, por supuesto, cuyo clamor todos conocían, y los amigos del difunto, naturalmente. Y Tácito, que ha recogido la tradición favorable al afecto entre Druso y Germánico, quiere igualmente poner en primer plano el papel que, en la medida que le era dado, y llevado de su deseo de justicia para con su hermano, quiso desempeñar Druso. Por ello, cuando Pisón, que, en su soberbia, ha perdido el norte, visita a Druso en el Ilírico, y cree que el joven se mostrará "más comprensivo" porque le han quitado de en medio al rival (III 8), halla un Druso que le responde que si uera forent quae iacerentur praecipuum in dolore suum locum, es decir, un Druso que clama justicia, si es verdad que Pisón ha tenido algo que ver con la muerte de su hermano (ib.).

Por ello, antes que con nadie, la conexión de Druso con el juicio se establece desde el primer momento (cap.7): la ciudad regresa a las tareas habituales, y Druso marcha al Ilírico, en medio de la expectación colectiva por la venganza de Pisón y la queja generalizada porque, a juicio de la gente, éste destruía las pruebas, al tiempo que se divertía en Asia y en Acaya; de esa conexión se deduce inmediatamente la visita de Pisón a Druso en la provincia, así como la marcha de aquél a Roma desde la misma (y no es que "obligado" por el encuentro en Dalmacia el autor prepare la visita en el cap. 
7, sino al revés, deseando mostrar el interés de Druso en el juicio, narra este encuentro previo, que realza con la debida antelación).

En efecto, en cap. 7 se afirma que tras el levantamiento del iustitium Druso marcha al Ilírico, y en el cap. 11 se nos dice que vuelve instantes antes de comenzar el juicio. ¿Cuándo marcha Druso a su provincia? Como el iustitium se ha levantado por un edicto (6) que después de justificar su levantamiento con ejemplos históricos recomienda a la ciudadanía la vuelta a sus tareas y a las diversiones, y éstas son el espectáculo de los juegos megalesios cuya celebración era del 4 al 10 de abril juegos que estaban al caer (suberant), y como por otra parte el iustitium se había decretado el 8 de diciembre, no tendría nada de extraño que el levantamiento se produjese poco después del 8 de marzo, a los tres meses de su promulgación; pues no creo que lo de los juegos debamos entenderlo en el sentido de que eran al día siguiente, y, dada la necesidad que tenía Tiberio de suprimir el iustitium, con una fecha de 15 o 20 días antes de los juegos se puede calificar a éstos de “inminentes". Por ello, Druso ha podido partir para el Ilírico a mediados de marzo, y haber llegado allí en nueve días, si ha marchado a la velocidad que se circuló con las cenizas de Germánico desde Terracina $(103 \mathrm{kms}$. en un solo día - III 2 y 5) a Roma, o bien rebajando esa velocidad a 70 kms., pongamos por caso, en trece o catorce días. De modo que a finales de marzo ha podido estar en su provincia. Allí se entrevista con Pisón hacia el 10 de abril, y a continuación el excónsul emprende la marcha a Roma, para llegar a la cual, tras la travesía del Adriático, toma en Ancona la vía Flaminia, que hasta Roma le lleva siete días (aun cuando parte del viaje lo haga por el río). Ello quiere decir que en quince o dieciséis días puede estar en Roma, y entrar en ella el 25 de abril. Al día siguiente se produce la cita judicial: 26 de abril (III 10: postera die).

Por su parte, Druso, sabedor asimismo de que Pisón ha partido para Roma, donde le aguarda el juicio, una vez resueltos los asuntos más urgentes de su administración en Dalmacia, se pone igualmente en camino a Roma, para asistir al juicio con el que se quiere vengar a su hermano, Germánico. Por ende, Druso puede haber salido del Ilírico el 20 de abril, con lo cual ha permanecido en su provincia tres semanas, más tiempo del que permaneció su padre con ocasión del viaje de éste a la misma provincia en el verano del año 14, cuando nada más llegar a la provincia tuvo que volver, llamado urgentemente por su madre ante la gravedad de la enfermedad de Augusto (I 5). Y 
esa es la nueva mención de Druso (III 11), su vuelta a Roma, que coincide con el breve compás de espera abierto tras la citación judicial de Pisón. Dicho compás de espera tiene dos partes:

a) petitum est a principe ut cognitionem acciperet;

b) paucis familiarium adhibitis minas ... et preces audit integramque causam ad senatum remittit (III 10).

¿Cuánto tiempo puede necesitar esto? Ginsburg, p. 59, dice: «We may suppose a few days between Piso's arrival in the city and the beginning of the trial during which Tiberius remitted the case to the senate and Piso secured representatives for his defense. (...) All of this accords well with the interval between the ludi Megaleses in April and the next datable event of this year, the ouatio of Drusus in May 28th».

En primer lugar, ¿no se tratará de puro formulismo? Pues, como hemos señalado más arriba, la acusación contra Pisón está trabajando directamente en Roma (cabe que ya antes de la llegada de Agripina a la ciudad hubiesen pedido por escrito a Tiberio justicia con Pisón) para que Tiberio ejerza su autoridad y facilite el juicio cuanto antes. Es posible que ello sea desde mediados de enero, digamos (de modo que cuando Pisón llega a Roma, la "instrucción" del caso está más que concluida, y el juicio puede empezar). Por consiguiente, la petición al príncipe es cuestión de un día. A continuación, Tiberio escucha las partes en pétit comité y devuelve la causa al senado: ¿Dos días? ¿Tres? En este momento, llega Druso, y se nombran defensores: Lépido, Pisón y Livineyo (un día más). Por tanto, si la cita judicial se produce el 26 de abril, el juicio puede comenzar (die senatus: III 12) cinco días o una semana más tarde; digamos el 5 de mayo. Por consiguiente. Druso ha podido llegar a Roma el 2 ó 3 de mayo.

Por si fuera poco, no contento con haber vinculado tan íntimamente el juicio de Pisón con la figura de Druso, Tácito remata la faena escogiendo para poner broche final al proceso precisamente la ouatio prometida por los padres (II 64, año 18), tanto a él como a Germánico, y al día siguiente de la terminación del juicio, Tácito nos revela (III 19): at Drusus urbe egressus repetendis auspiciis mox ouans introiit. Y los Fastos Ostienses conservan la fecha: 28 de mayo del año 20.

En III 11, cuando Druso regresa a Roma el 2 ó 3 de mayo para asistir al juicio, Tácito hace hincapié en que, pese a que los padres habían decretado su ouatio, pospuso ésta y entró en la ciudad con toda normalidad. En primer 
lugar, sorprende la insistencia en ese detalle, porque en marzo Druso estaba en Roma, en la que había entrado, no sabemos cuándo, proveniente presumiblemente del Ilírico; y no sólo en marzo, también en enero se hallaba en la ciudad, puesto que sale hasta Terracina a acompañar los restos de Germánico. Como, por otra parte, Livia, su esposa, ha tenido los gemelos a finales de diciembre del año anterior, es de creer que, si no otro motivo anterior, ha sido el parto de la cónyuge el que le ha traído a Roma, y por tanto podemos colegir que Druso ha vuelto del Ilírico como muy tarde a primeros de diciembre (coincidiendo además con la confirmación definitiva de la muerte de Germánico y la declaración del iustitium el día 8 de ese mes). Pero, claro, no eran esos días para celebrar nada: Germánico había muerto en extrañas circunstancias y su esposa se iba a poner de parto, y además era el mes de diciembre, poco propicio, me parece, para tales desfiles. Por lo tanto, es ahora, al volver a principio del mes de mayo, cuando Druso podía haber celebrado su ouatio, sólo que el juicio de Pisón por la muerte de su hermano, Germánico, estaba en curso y no parecía decente semejante celebración en medio del mismo.

De modo que lo que hay que destacar, una vez demostrada la causa de la vinculación de Druso con el juicio, es que dicho juicio se vincula a su vez íntimamente con la ouatio y no sólo porque el broche final es la celebración de la misma, como se encarga de decirnos Tácito, sino también porque a la vuelta de Druso del Ilírico para asistir al juicio lo único que se pone de relieve es precisamente que no celebra la ouatio. Por lo tanto, no es una sola vez, sino las que el historiador conecta o relaciona juicio y ouatio de Druso: sólo un loco podría poner dos veces la ouatio en relación con un juicio finalizado el 10 de diciembre, haciendo creer, primero, que Druso regresa, p. ej., en octubre y pospone su celebración, y afirmando, segundo, que Druso celebra la ouatio tras finalizar el juicio, por tanto, el 28 de diciembre, si el mismo individuo es sabedor de que el triunfo se ha celebrado el 28 de mayo y de que, por tanto, la posposición ha tenido que ser necesariamente antes del 28 de mayo, de suerte que por dos veces incurra en engaño histórico, sin que por otra parte se vea la más leve razón para ello, pues, como hemos dicho más arriba, con eliminar las referencias a Druso de capp. 7 y 8, la narrativa quedaba perfectamente coherente, e incluso también nombrando a Druso en ambos capp. y eliminando las dos menciones de la ouatio cuya función, de no haber existido la posposición de 
la ouatio ni la misma en la época "real", no venía a cuento, se mire por donde se mire.

¿Equivocación de Tácito? En este caso, la equivocación sería triple:

$1^{\circ}$. Pospone la ouatio en sept., oct. o nov., y es en mayo (o abril).

$2^{\circ}$. Celebra la ouatio en 28 de diciembre y es en 28 de mayo.

$3^{\circ}$. Admite (ante sus ojos se halla la documentación, el SCPP incluido) la ouatio en pleno diciembre, un mes, a mi juicio, poco adecuado para festejos. Pero además, Tácito no puede olvidarse de que el año 17 lo ha comenzado justamente con el triunfo de Germánico, que se celebró precisamente el 26 de mayo, exactamente tres años antes que Druso, y el historiador no deja de significar que esos tres años son los que separan los honores de Druso (consulado, triunfos, etc.) de idénticos honores de su primo hermano: Germánico = cónsul en 12 y 18, triunfo en 18; Druso = cónsul en 15 y 21, triunfo (ouatio) en 20 (idénticos meses y fechas). Creer que Tácito se ha ofuscado en esta ocasión es creer en lo excusado.

En definitiva, por lo que acabamos de ver un error o equivocación es impensable e increíble; un engaño, injustificable e innecesario. Y si no es un error ni un engaño, sólo queda una opción: la época que sugiere Tácito para el juicio de Pisón es la época en que el juicio tuvo lugar de verdad.

Por lo demás, pensamos que el juicio duró del 5 al 20 de mayo (cap. 1118), y que, transcurrido un nundinum, Druso pudo entrar y, una vez hecha justicia con su hermano, celebrar finalmente la ouatio.

\section{La legio IX Hispana}

Otro dato relacionado con la celebración del juicio y su tiempo es el encuentro de Pisón con la legión IX (III 9) en la Vía Flaminia, a cuyo respecto caben dos posibilidades:

1. El juicio es en diciembre y Pisón llega a Roma en septiembre u octubre (Caballos, etc., p. 148). Entonces:

$1^{\circ}$. Como Pisón y la legión se cruzan en la vía Flaminia los días previos a la llegada del primero a Roma, la legión a su vez llegará al África a finales de octubre o ya en noviembre (desde la vía Flaminia la legión ha de llegar a Roma, descender hasta Ostia y embarcar al África - $450 \mathrm{~km}$. -, lo que implica unas tres semanas de viaje).

$2^{\circ}$. Como entra efectivamente en combate (III 21: quis uelocissimos legionum addiderat), ha de hacerlo a esas alturas del año ${ }^{3}$.

3 Pero, ¿cómo es posible que Tiberio ordenase a esas alturas del año - en el mes de sep- 
$3^{\circ}$. Pero ello es imposible, porque la campaña de África se desarrolla exclusivamente durante el verano ${ }^{4}$.

$4^{\circ}$. Luego Pisón y la IX no se han cruzado en la Vía Flaminia.

2. El juicio es en diciembre, pero Pisón llega a Roma en mayo. Entonces:

$1^{\circ}$. Como la guerra tiene lugar durante el verano, la legión llega al África en mayo o junio, a lo sumo.

$2^{\circ}$. Ello implicaría que, en caso de haberse cruzado con Pisón en la Vía Flaminia, el encuentro ha tenido lugar en mayo.

$3^{\circ}$. En tal caso, Pisón no llega a Roma en septiembre o en octubre, sino en dicho mes de mayo.

$4^{\circ}$. Con lo que si, pese a todo, persistimos en poner el juicio en diciembre, el reo ha debido esperar para el mismo no dos meses (octubre y noviembre), sino siete meses (mayo-noviembre), lo que a todas luces resulta completamente absurdo. Luego el encuentro de Pisón con la legión IX Hispana implica que el juicio tiene lugar en mayo y no en diciembre.

\section{El caso de Lépida y su relación con el juicio.}

Los ludi de III 23 han de ser los de septiembre, pues la guerra es en verano, y la narrativa avanza. Por otro lado, la frase de III 24 haud multum dis-

tiembre u octubre - cuando la época de guerra normalmente está terminada, el traslado de la legión desde un punto tan lejano hasta el norte de África? ¿Tan crítica era la situación? Pero Tiberio no se dejaba fácilmente conmover por amenazas de guerra (como se demostrará con la rebelión de las Galias en el año 21, y ya había puesto de manifiesto a propósito de los motines de Panonia y Germania en el año 14), ni la situación era tan crítica: la guerra de África había comenzado ya en el año 17 y no concluirá hasta cuatro años más tarde (año 24). Del mismo modo que en los tres o cuatro años anteriores el emperador veía que no se había acabado la guerra, no se vé por qué va a envidar tanto en una época tan avanzada del año (otoño), en que, proveniente de Panonia en esa época del año la legión tenía que encontrar necesariamente dificultades casi insalvables al toparse con la nieve de los Apeninos (cf. Historias III 59: sed foeda hieme per transitum Appennini conflictatus exercitus, et uix quieto agmine niues eluctantibus patuit quantum discriminis adeundum foret, año 69, aunque para un mes, o así, más tarde), si la experiencia le dictaba que si no terminaba un año ya se concluiría el siguiente. Por otra parte, ¿cuál fue el resultado de la guerra? Una prosperam aduersum Numidas pugnam y el rechazo de los enemigos al desierto. ¿Y para eso una movilización tan complicada en una época inhabitual?

4 Ginsburg, p. 36: «The words priore aestate (III 20) are a tacitean error of chronology, but they nonetheless indicate the time of year for the campaign of 17». Cf., además, III 74 (año 22) nec ... acta aestate y IV 27 (año 24) eadem aestate, ambas veces referido a la guerra de África. 
tanti tempore Calpurnii Pisonem, Aemilii Lepidam amiserant, que los defensores del juicio en diciembre interpretan bonitamente diciendo que «Tácito sólo permanece fiel a la sucesión de su propia narración» (Caballos, etc., p. 147), y que por tanto no aporta ninguna luz para resolver el problema, no conviene despacharla tan cómodamente, pues, en primer lugar, si citase los nombres al revés, también cabría decir que se expresa en quiasmo (Aemilii-Calpurnii) y que ello no era más que un recurso estilístico que no implicaba orden cronológico estricto: cita primero a los Emilios porque son los que acaba de nombrar, y luego recoge también el caso, más lejano ya, de los Calpurnios, sin que ello implique orden temporal. Y en segundo lugar, ¿por qué no va a implicar secuencia cronológica real? Simplemente, Tácito sabe que los Calpurnios sufrieron antes la pérdida y por ello los cita en primer término, y lo mismo, que los Emilios la sufrieron de spués, de donde que los cite en segundo lugar. Simplemente.

\section{La prueba del método cronológico-estructural}

En un trabajo todavía inédito («El método cronológico-estructural en los Anales de Tácito») he estudiado minuciosamente la manera en que este autor combina en su narrativa histórica el tiempo real o tiempo histórico, dentro del cual tienen lugar los acontecimientos que narra, con las necesidades literarias y estructurales indispensables, combinación que permite obtener el producto intensamente dramático que todos conocemos, sin que por ello falte el historiador a la verdad histórica.

Conviene, para simplificar, decir en primer término que el carácter de lo que se narra es, desde el punto de vista literario, doble, a saber, narrativo, propiamente dicho, e informativo, entendiendo por lo primero aquellos acontecimientos susceptibles de ser narrados articuladamente en su progresión temporal natural, con principio, medio y fin, en tanto que por informativo hemos de entender aquellas noticias pobres y dispersas, acerca de las cuales no se narra, sino simplemente se informa de manera no durativa, sino puntual.

Por otra parte, la analística romana atendía cuasi mecánicamente a una dicotomía narrativa según que los hechos relatados fuesen referidos a Roma (y, diríamos también, Italia) o de fuera de Roma (e Italia), es decir, las provincias romanas y los pueblos bárbaros. Conforme a esta cuádruple división, 
la estructura narrativa en los Anales puede adoptar las cuatro siguientes formas:

a) Narración interior propiamente dicha, esto es, acerca de hechos referidos en la línea del tiempo, uno detrás del otro y correspondientes a Roma.

b) Información de hechos igualmente del interior pero sin preocupaciones cronológicas ("cajón de sastre atemporal").

c) Narración propiamente dicha, pero de hechos exteriores en secuencia cronológica. Esto es, uno detrás del otro.

d) Narración de hechos exteriores, pero tan resumidamente que aunque se adivina la evolución de los acontecimientos, su cronología precisa es difícil de seguir, sencillamente porque el autor se desentiende de ella, cosa que confiesa en más de una ocasión ("bloque errático").

Pues bien, en tanto que el cajón de sastre tiende sistemáticamente a ubicarse a final del contenido anual, el bloque errático puede, amén de ocupar esa posición, la más habitual, situarse al principio o en medio. Y mientras que el cajón de sastre y, en parte, el bloque errático, se sitúan, por así decir, al margen del tiempo (si bien en el cajón hay también referencias cronológicas rudimentarias y en el bloque secuencias claras, por más que vagas), la narración propiamente dicha, tanto la de interior como la de exterior, obedece a una estricta secuencia temporal. $\mathrm{Y}$ en este punto, debemos anticiparnos a decir que de los 43 años sobre los que nos ha llegado algo en el estado actual de la transmisión de los Anales y si exceptuamos 3 de dichos años (29, 34 y 57), cuyo pobre contenido no permite trazar su calendario, de los 43 años restantes, 15 presentan una secuencia temporal referida exclusivamente a hechos interiores, 1 , referido exclusivamente a hechos exteriores, y 8 , una secuencia temporal en la que alternan los hechos exteriores y los interiores, $o$ viceversa, a los que hay que añadir otros 11 años más, en los que a dicha secuencia (simple o compuesta) se le adjunta un bloque errático, que como tal se muestra temporalmente independiente (hacemos abstracción de los casos con cajón de sastre atemporal, dada su nula repercusión cronológica por mor de su carácter meramente informativo). Todavía, hay 5 años en los que se establecen dos líneas narrativas total o parcialmente paralelas (años 17, $18,22,26$ y 62 ).

Al margen de otras características que ahora no vienen a cuento, sí nos interesa poner de relieve el hecho importante de que la prosecución temporal (unos sucesos detrás de otros) no sólo halla cabida en los años lineales sim- 
ples (esto es, que narran acontecimientos o puramente interiores o puramente exteriores), sino igualmente en los años compuestos o mixtos (esto es, aquellos que alternan exterior con interior, o viceversa, de tal modo que, si, p. ej., en la primera parte del año se han referido hechos interiores, a continuación pueden venir hechos exteriores, p. ej., del verano, y luego, otra vez, hechos interiores del otoño, etc.), siendo así que el historiador goza de la libertad tanto del cajón de sastre para hechos interiores salpicados a lo largo del año que no han podido ser recogidos en la secuencia narrativa anterior como del bloque errático para resumen de hecho exteriores en períodos que rebasan el cauce anual.

Fijémonos, para lo que aquí nos interesa, en los años que suman interior/exterior/interior, etc. Hemos dicho que son 8 por un lado, más (especifiquemos ahora) 7, por el otro (número del tipo compuesto o mixto: interior/exterior, de entre los 11 dotados de bloque errático). Si decidimos representar semejante secuencia de manera esquemática, obtendremos esquemas de los siguientes tipos:

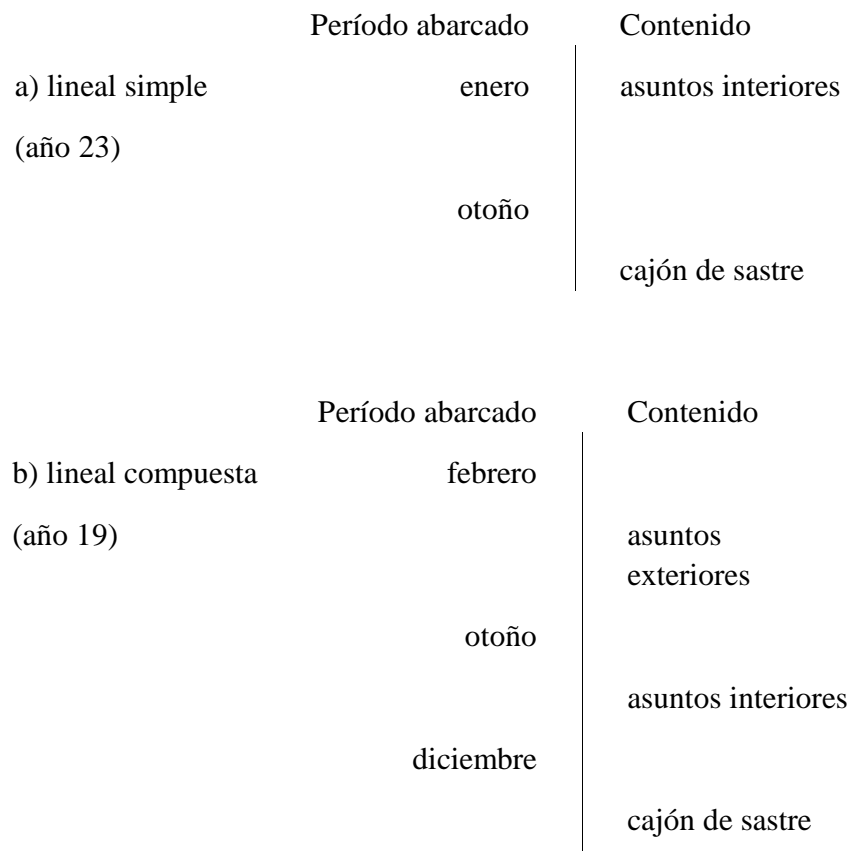




\begin{tabular}{|c|c|c|}
\hline \multirow[b]{2}{*}{$\begin{array}{l}\text { c) con bloque } \\
\text { errático }\end{array}$} & Período abarcado & Contenido \\
\hline & & bloque errático \\
\hline \multirow[t]{6}{*}{ (año 17) } & enero & \\
\hline & & asuntos exteriores \\
\hline & verano & \\
\hline & & asuntos interiores \\
\hline & otoño & \\
\hline & & cajón de sastre \\
\hline
\end{tabular}

d) ramificados o en paralelo (con dos líneas total o parcialmente paralelas):

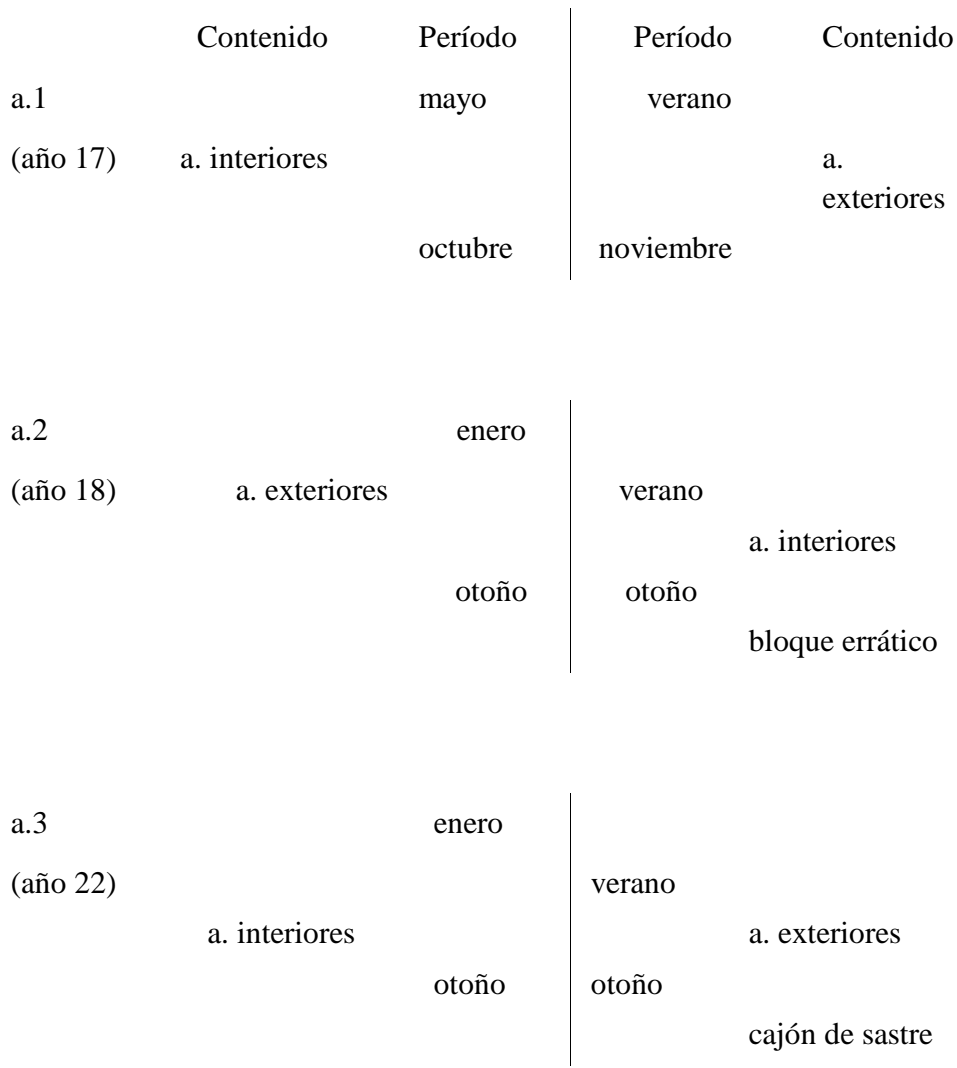


a.4

\begin{tabular}{ll|ll} 
& enero & & \\
a. exteriores & & verano & \\
& otoño & diciembre &
\end{tabular}

El esquema correspondiente al año 62 es el más complejo de todos, puesto que en este año encontramos, primeramente, un tramo de estructura lineal simple - a) -, que se extiende de enero a diciembre, se dedica a asuntos interiores y termina con un cajón de sastre atemporal, y un segundo tramo de estructura ramificada, o en paralelo, que puede representarse mediante el siguiente esquema:

\begin{tabular}{cc|cc} 
Contenido & Período & Período & Contenido \\
bloque errático & enero & & \\
a. exteriores & & verano & \\
& diciembre & atoño & \\
bloque errático & & cajón de \\
& & sastre
\end{tabular}

Pues bien, cualquiera de los 32 restantes años apuntados en los Anales responderá a uno de estos diseños (con distintas combinaciones, lógicamente, de asuntos interiores, asuntos exteriores, extensión temporal, y presencia o no de cajón de sastre o bloque errático). Es así como el año 20, el año en cuestión en el presente trabajo, cuyo contenido, según la tesis tradicional aquí defendida, es:

- En enero se celebra el entierro de las cenizas de Germánico en el mausoleo de Augusto; en marzo se levanta el iustitium y Druso marcha al Ilírico; en abril se ven Pisón y Druso en dicha provincia; a finales de abril llega Pisón a Roma, a comienzos de mayo lo hace Druso; el 5 de mayo comienza el juicio, que termina el 20; el 28 se celebra la ouatio (período enero-junio). 
- Empieza la guerra de África (verano), después de la cual viene el juicio de Lépida, el regreso de Silano, el tratamiento de la ley Papia Popea; más tarde, la petición al senado a favor de Nerón (con cajón de sastre atemporal) y a fin de año (fine anni) un par de obituarios (período otoño-diciembre).

Pero a tenor de la opinión de los que creen que el juicio se celebró en diciembre, habría de aceptar una distribución de hechos como la siguiente (dos posibilidades):

A):

1) enero-diciembre = entierro, juicio, ouatio $(?)=$ asuntos interiores.

2) verano (vuelta atrás) $=$ guerra de África $=$ asuntos exteriores.

3) otoño-diciembre = Lépida, Silano, ley Papia Popea, petición al senado, obituarios $=$ asuntos interiores.

B):

1) enero-diciembre $=$ entierro, juicio, triunfo $(?)=$ asuntos interiores.

2) verano (vuelta atrás) = guerra de África $=$ asuntos exteriores.

3) primavera (pero Druso no estaría en Roma, si acaba de marchar al Ilírico, y Tácito afirma que durante el juicio de Lépida se hallaba en Roma (III 22: exemit Drusum consulem designatum dicendae primo loco sententiae) = Lépida, Silano, ley Papia Popea, petición al senado (que en este caso coincidiría con la fecha del 7 de junio, que los Fastos dan para la toma de la toga viril por Nerón, hijo de Germánico), y luego, salto de junio a diciembre para los obituarios.

Pues bien, este año 20 que estamos estudiando, tendría las tres siguientes representaciones esquemáticas de acuerdo con las tres propuestas de secuencia temporal descritas aquí arriba.

En consonancia con nuestra tesis:

\begin{tabular}{l|l} 
Contenido & \multicolumn{1}{|c}{ Período } \\
$\begin{array}{l}\text { asuntos interiores } \\
\text { asuntos } \\
\text { exteriores }\end{array}$ & verano \\
asuntos interiores & otoño \\
cajón de sastre & noviembre
\end{tabular}


Esquema, que, como fácilmente se ve, sería absolutamente normal. Y si aceptáramos la tesis del juicio celebrado en diciembre, los esquemas correspondientes a las dos alternativas presentadas más arriba serían los siguientes:

a) manteniendo el juicio de Lépida en otoño:

\begin{tabular}{lr|ll} 
Contenido & Período & Período & Contenido \\
& enero & verano & \\
a. interiores & & atoño & \\
& diciembre & noviembre & a. interiores \\
& cajón de sastre
\end{tabular}

b) retrotrayendo el juicio de Lépida, como quieren algunos, a la primavera:

\begin{tabular}{|c|c|c|c|}
\hline Contenido & Período & Período & Contenido \\
\hline \multicolumn{4}{|c|}{ enero } \\
\hline a. interiores & & primavera & \\
\hline & verano & & a. interiores \\
\hline a. exteriores & & noviembre & \\
\hline & diciembre & & cajón de sastre \\
\hline
\end{tabular}

Fácil es percatarse de que, en ambos casos, el esquema resultante no se corresponde con ninguno de los esquemas normales reseñados arriba, sino que, por el contrario, ambos diseños son absolutamente aberrantes. Luego la estructura y secuencia temporales subyacentes en estos dos esquemas anómalos son aberrantes, razón por la cual nos vemos obligados a volver al esquema por nosotros propuesto. Luego el juicio de Pisón no se celebró en el mes de diciembre. Luego dicho juicio tuvo lugar, conforme con el esquema normal, en primavera. De este modo, resulta claro, más allá de toda duda razonable, que el juicio de Gneo Calpurnio Pisón tuvo lugar, como se trasluce de la narración de Tácito, en mayo del año 20, y de ninguna manera en el 
mes de diciembre, época a la que corresponde el senadoconsulto, cuyo objetivo, puramente político, aconsejó su emisión en dicha época, a seis meses y medio de la celebración del juicio y suicidio de Pisón.

BIBLIOGRAFÍA

Caballos A., Eck W., Fernández, F.: El senadoconsulto de Gneo Pisón padre, Sevilla, 1996. Ginsburg, J.: Tradition and Theme in the Annals of Tacitus, New York, 1981.

González, J., Estudios sobre la Tabula Siarensis, Madrid, 1988.

Koestermann, E.: Cornelius Tacitus. Annalen. Bd. I Buch 1-3, Heidelberg, 1963-

Woodman, A.J. and Martin, R.H.: The Annals of Tacitus. Book 3, Cambridge, 1996. 